\title{
New hole-transport polyurethanes applied to polymer light-emitting diodes
}

\author{
Kun-Rung Lin ${ }^{\text {a }}$, Chao-Hui Kuo ${ }^{\text {a }}$, Li-Chung Kuo ${ }^{\mathrm{c}}$, Kuei-Hui Yang ${ }^{\mathrm{c}}$, \\ Man-kit Leung ${ }^{\mathrm{a}, \mathrm{c}, *}$, Kuo-Huang Hsieh ${ }^{\mathrm{a}, \mathrm{b}, *}$ \\ a Institute of Polymer Science and Engineering, National Taiwan University, No. 1, Section 4, Roosevelt Road, Taipei 10617, Taiwan \\ b Department of Chemical Engineering, National Taiwan University, No. 1, Section 4, Roosevelt Road, Taipei 10617, Taiwan \\ ${ }^{\mathrm{c}}$ Department of Chemistry, National Taiwan University, No. 1, Section 4, Roosevelt Road, Taipei 10617, Taiwan
}

Received 31 May 2007; received in revised form 18 July 2007; accepted 20 July 2007

Available online 27 July 2007

\begin{abstract}
Polymeric light-emitting diodes (PLEDs) using high-performance hole-transport polyurethanes (PUs) have been fabricated. The PUs were prepared from the condensation polymerization of $(E, E)$-1,4-bis(2-hydroxystyryl)benzene, an oligo para-phenylene- $(E)$-vinylene (OPV) unit, with toluene diisocyanate (TDI), isophorone diisocyanate (IPDI) or dicyclohexylmethane 4,4'-diisocyanate $\left(\mathrm{H}_{12} \mathrm{MDI}\right)$, respectively. The condensation polymerization was end-capped with 4-tert-butylphenol as the terminal group. The PLED having the PU layer inserted between PEDOT:PSS (HIL) and MEH-PPV (EML) demonstrated superior current efficiency and low turn-on voltage when comparing to the reference devices of ITO/MEH-PPV $(50 \mathrm{~nm}) / \mathrm{Ca}(10 \mathrm{~nm}) / \mathrm{Ag}(100 \mathrm{~nm})$ as well as ITO/PEDOT:PSS $(30 \mathrm{~nm}) / \mathrm{MEH}-\mathrm{PPV}(50 \mathrm{~nm}) /$ $\mathrm{Ca}(10 \mathrm{~nm}) / \mathrm{Ag}(100 \mathrm{~nm})$. In particularly, the best device performance was realized with the PU of OPV-IPDI as the hole-transport layer, resulting 53 times and 2.72 times of current efficiency enhancement as well as $1.5 \mathrm{~V}$ and $1 \mathrm{~V}$ voltage reduction of the turn-on voltage, respectively, when compared against the reference devices. Besides, our experiments also showed that the PU polymer could also be applied for flexible PLED with similar performance enhancement. Based on the promising results, we concluded that OPV-IPDI was a good hole-transport material for light-emitting diode application. (C) 2007 Elsevier Ltd. All rights reserved.
\end{abstract}

Keywords: Polymeric light-emitting diodes (PLEDs); Polyurethanes (PUs); Hole-injection layer (HIL); Hole-transport layer (HTL); Poly[2-methoxy-5-(2'-ethyl-hexyloxy)-1,4-phenylene-vinylene] (MEH-PPV); Emitting layer (EML)

\footnotetext{
${ }^{*}$ Corresponding authors. Present address: Institute of Polymer Science and Engineering, National Taiwan University, No. 1, Section 4, Roosevelt Road, Taipei 10617, Taiwan. Fax: +8862 23627688 (K.-H. Hsieh); +886 223636359 (M.-k. Leung).

E-mail addresses: mkleung@ntu.edu.tw (M.-k. Leung), khhsieh@ntu.edu.tw (K.-H. Hsieh).
}

\section{Introduction}

Polymeric light-emitting diodes (PLEDs) [1-3] have attracted much interest during the last two decades due to their low driving voltage, wide color gamut, low cost and ease of processing. In addition, they are potentially useful for flexible large-area full-color panel displays [4]. The performances of 
organic LED devices are governed by many factors, including balanced injection of charge carriers, quantum efficiency of the light-emitting process, and the charge confinement for bipolaron recombination [5-7]. To achieve high efficient devices, multilayer OLED structures have been commonly adopted to optimize the device performance. However, applying the concept of multi-layer structures to PLED devices is somewhat challengeable because typical solvents such as chloroform, toluene or xylene have good etching ability for many polymers and would non-selectively destroy most of the precoated polymeric layers. Therefore, fabrication of multi-layer PLED devices through layer-by-layer spin-coating or inkjet printing would be difficult [8].

In order to establish the multi-layer polymer devices, many different approaches have been reported to bypass the solubility problem. One of the solutions is to make polymeric film insoluble by thermal treatments $[1,9]$ or photochemical cross-linking prior to the processing of the subsequent layer [10].

An alternative approach is to have polymers that are dissolved, respectively, in polar and non-polar solvent systems [11]. Since some well-known lightemitting polymers such as poly(para-phenylene(E)-vinylenes) [12], or polyfluorenes [13] are soluble in non-polar solvents, therefore, electron and holetransport polymers that are soluble in polar solvents are highly desired. A typical example is the twolayer structure device derived from the wide-used water soluble PEDOT:PSS and non-polar lightemitting polymers [12e].

Polyurethanes (PUs) are common polymers that have been widely used for industrial applications [14]. Due to their big contrast of good solubility in polar solvents such as DMF, or NMP in comparison to their poor solubility in non-polar solvents, they are appropriate candidates to study $[15,16]$. In this article, synthesis and study of the hole-transport polyurethanes (PUs) as well as their application to high-efficiency multi-layer PLED devices are reported.

\section{Experimental}

\subsection{Materials synthesis [15a]}

\subsubsection{Tetraethyl $\alpha, \alpha^{\prime}$-para-xylenediphosphonate (1)}

To a two-necked flask was added $N$-bromosuccinimide $(160 \mathrm{~g}, 0.9 \mathrm{~mol})$, para-xylene $(43.7 \mathrm{~g}$, $0.41 \mathrm{~mol})$ and methyl formate as solvent $(388 \mathrm{~mL})$.
The mixture was irradiated by a sun-lamp $(120 \mathrm{~W})$ for $20 \mathrm{~min}$ at room temperature with stirring. AIBN $(0.044 \mathrm{~g}, 0.27 \mathrm{mmol})$ was then added to initiate the radical bromination. The mixture was heated to $40{ }^{\circ} \mathrm{C}$ and irradiated for $14 \mathrm{~h}$, and then cooled to room temperature. White precipitates formed were collected by filtration and washed with small portions of methyl formate. The collected precipitates contained the desired $\alpha, \alpha^{\prime}$-dibromo-para-xylene and succinimide. The succinimide was removed by washing with water. The white crude product was dried and recrystallized from chloroform to give white needles $(54 \mathrm{~g}, 0.21 \mathrm{~mol}, 51 \%)$. M.p. 142 $143{ }^{\circ} \mathrm{C}$ [lit. $143.5^{\circ} \mathrm{C}$ ] [17], ${ }^{1} \mathrm{H}$ NMR $(200 \mathrm{MHz}$, $\left.\mathrm{CDCl}_{3}\right), \delta 7.35(\mathrm{~s}, 4 \mathrm{H}), 4.45(\mathrm{~s}, 4 \mathrm{H}) ;{ }^{13} \mathrm{C} \mathrm{NMR}$ $\left(100 \mathrm{MHz}, \mathrm{CDCl}_{3}\right) \delta 138.0,129.5,32.8$. MS $\mathrm{m} / z$ FAB (NBA) HRMS $\left(\mathrm{M}^{+}\right)$calcd. for $\mathrm{C}_{8} \mathrm{H}_{8} \mathrm{Br}_{2}$ 261.8993, found $\mathrm{C}_{8} \mathrm{H}_{8} \mathrm{Br}_{2}$ 261.8997; IR (KBr): $3034,1229,2977,612 \mathrm{~cm}^{-1}$.

To an oven-dried double-necked flask containing a stir bar were charged $\alpha, \alpha^{\prime}$-dibromo-para-xylene $(10.0 \mathrm{~g}, 38.0 \mathrm{mmol})$ and triethyl phosphite $(13.8 \mathrm{~g}$, $83 \mathrm{mmol})$. The flask was repeatedly evacuated and flushed with argon for several times. The reaction mixture was stirred and heated at reflux temperature for $21 \mathrm{~h}$, and was cooled to room temperature. The excess triethyl phosphite was removed by distillation under reduced pressure. The white solid left inside the flask was collected and recrystallized from ether to give white crystals $(9.45 \mathrm{~g}, 25 \mathrm{mmol}, 66 \%)$. M.p. $45-46{ }^{\circ} \mathrm{C}$. [lit. $70{ }^{\circ} \mathrm{C}$ from hexane] [18], ${ }^{1} \mathrm{H}$ NMR $\left(200 \mathrm{MHz}, \mathrm{DMSO}-d_{6}\right): \delta 7.20(\mathrm{~s}, 4 \mathrm{H}), 3.92$ (quintet, $J=7.2 \mathrm{~Hz}, 8 \mathrm{H}), 3.18\left(\mathrm{~d}, J_{\mathrm{HP}}=20.1 \mathrm{~Hz}\right.$, $4 \mathrm{H}), 1.15(\mathrm{t}, J=7.0 \mathrm{~Hz}, 12 \mathrm{H}) ;{ }^{13} \mathrm{C} \mathrm{NMR}(100 \mathrm{MHz}$, DMSO- $\left.d_{6}\right): \quad \delta \quad 135.6, \quad 134.8, \quad 66.5, \quad 37.1 \quad(\mathrm{~d}$, $J \mathrm{cp}=130 \mathrm{~Hz}), \quad 21.4 ; \quad \mathrm{MS} \quad m / z \quad$ FAB $\quad(\mathrm{NBA})$ $\left(\mathrm{M}^{+}+\mathrm{H}\right)$ 379.14; HRMS $\left(\mathrm{M}^{+}\right)$calcd. for $\mathrm{C}_{16} \mathrm{H}_{28} \mathrm{O}_{6} \mathrm{P}_{2} \quad 378.1361$, found $\mathrm{C}_{16} \mathrm{H}_{28} \mathrm{O}_{6} \mathrm{P}_{2}$ 378.1366. IR (KBr) 2990, 1517, 1233, $1054 \mathrm{~cm}^{-1}$.

\subsection{2. (E,E)-1,4-Bis(2-hydroxystyryl)benzene $(O P V)$}

To a two-necked flask were added 2-hydroxybenzaldehyde $(11.4 \mathrm{~g}, \quad 0.10 \mathrm{~mol}), \quad$ (1) $\quad(10.4 \mathrm{~g}$, $27.4 \mathrm{mmol}), \mathrm{LiCl}(4.78 \mathrm{~g}, 0.11 \mathrm{~mol})$, and dried DMF $(58 \mathrm{~mL})$ as solvent. The mixture was first stirred at room temperature under nitrogen for $20 \mathrm{~min}$, and then pre-cooled in an ice bath, followed by addition of potassium tert-butoxide (24.6 g, $0.23 \mathrm{~mol}$ ) slowly. The reaction was continued for $5 \mathrm{~h}$ at room temperature under an inert atmosphere. Aqueous $\mathrm{HCl}(1 \mathrm{~N})$ was added slowly to quench the 
reaction until the solution turned acidic. The yellow precipitate was collected by filtration, washed with water and methanol and recrystallized from acetone to afford as yellow crystals $(6.5 \mathrm{~g}, 20.7 \mathrm{mmol}, 74 \%)$. M.p. $210-211^{\circ} \mathrm{C}$ [lit $230-231^{\circ} \mathrm{C}$ from DMF-ether] [19], ${ }^{1} \mathrm{H}$ NMR $\left(300 \mathrm{MHz}, \mathrm{DMSO}-d_{6}\right) \delta 9.79(\mathrm{~s}$, $2 \mathrm{H}), 7.59-7.54(\mathrm{~m}, 4 \mathrm{H}), 7.43(\mathrm{~d}, J=16.5,2 \mathrm{H})$, $7.21(\mathrm{~d}, J=16.5,2 \mathrm{H}), 7.09(\mathrm{t}, J=6.9,2 \mathrm{H}), 6.88$ $6.81(\mathrm{~m}, 4 \mathrm{H}) ;{ }^{13} \mathrm{C}$ NMR $\left(100 \mathrm{MHz}\right.$, DMSO- $\left.d_{6}\right) \delta$ $155.0,136.7,128.6,127.5,126.6,126.4,123.8$, 123.3, 119.3, 115.8; MS $m / z$ FAB (NBA) 314.1; HRFAB $\left(\mathrm{M}^{+}\right)$calcd. for $\mathrm{C}_{22} \mathrm{H}_{18} \mathrm{O}_{2} 314.38$, found $\mathrm{C}_{22} \mathrm{H}_{18} \mathrm{O}_{2}$ 314.1310. IR (KBr) 3511, 1491, 813, $763 \mathrm{~cm}^{-1}$.

\subsection{General procedures for the synthesis of $O P V$ - polyurethane}

OPV, diisocyanate (TDI, IPDI, $\mathrm{H}_{12} \mathrm{MDI}$ ) and dried DMF were first reacted, with stirring, in a two-necked flask for $24 \mathrm{~h}$ at room temperature under nitrogen. 4-tert-Butylphenol was added in order to terminate the polymerization. The mixture was further stirred for $24 \mathrm{~h}$. When the reaction was complete, the polymer was precipitated by dropwise addition of the reaction mixture into methanol. The process of dissolution in DMF and precipitation in $\mathrm{MeOH}$ was repeated for several times. The polymers were further precipitated in toluene to remove any toluene-soluble oligomers. The polymers obtained under this precipitation condition would have higher resistance against solvent-etching in the multi-step spin-coating process.

\subsection{1. $O P V-T D I$}

OPV (942 $\mathrm{mg}, 3 \mathrm{mmol}$ ), toluene diisocyanate (548 mg, $3.15 \mathrm{mmol}$ ), dried DMF $(15 \mathrm{~mL})$ and terminal group 4-tert-butylphenol (45 $\mathrm{mg}, 0.3 \mathrm{mmol})$ were used to afford $1.32 \mathrm{~g}$ white-yellow solid (yield, $89 \%$ ). M.p.: $214-215^{\circ} \mathrm{C}$. Calcd. for: C, 73.1; H, 7.1; $\mathrm{N}$, 5.22. Found: C, 71.5; H, 6.9; N, 5.3. ${ }^{1} \mathrm{H}$ NMR $\left(400 \mathrm{MHz}, \mathrm{DMSO}-d_{6}\right) \delta 3.9-4.2(\mathrm{~m}, 3 \mathrm{H}), 6.2-8.3$ (m, 28H).

\subsection{2. $O P V-I P D I$}

OPV (942 $\mathrm{mg}, 3 \mathrm{mmol}$ ), isophorone diisocyanate (700 mg, $3.15 \mathrm{mmol})$, dried DMF $(15 \mathrm{~mL})$ and terminal group 4-tert-butylphenol ( $45 \mathrm{mg}, 0.3 \mathrm{mmol}$ ) were used to afford $1.5 \mathrm{~g}$ light white solid (yield, 92\%). M.p.: $202-203{ }^{\circ} \mathrm{C}$. Calcd. for: C, 76.2; H, 6.8; N, 5.10. Found: C, 76.5; H, 6.8; N, 5.3. ${ }^{1} \mathrm{H}$
NMR $\left(400 \mathrm{MHz}, \mathrm{DMSO}-d_{6}\right) \delta 0.7-2.0(\mathrm{~m}, 18 \mathrm{H})$, 2.7-3.0 (m, 2H), 3.5-3.8 (m,1H), 6.7-8.1 (m, 20H).

\subsection{3. $O P V-H_{12} M D I$}

OPV (942 mg, $3 \mathrm{mmol}$ ), dicyclohexylmethane 4,4'-diisocyanate (825 mg, $3.15 \mathrm{mmol})$, dried DMF $(15 \mathrm{~mL})$ and terminal group 4-tert-butylphenol ( $45 \mathrm{mg}, 0.3 \mathrm{mmol}$ ) were used to afford $1.50 \mathrm{~g}$ white solid (yield, 85\%). M.p.: $189-190{ }^{\circ} \mathrm{C}$. Calcd. for: $\mathrm{C}, 78.1 ; \mathrm{H}, 6.5 ; \mathrm{N}, 5.02$. Found: $\mathrm{C}, 79.5 ; \mathrm{H}, 7.1$; $\mathrm{N}, 4.90 .{ }^{1} \mathrm{H}$ NMR $\left(400 \mathrm{MHz}, \mathrm{DMSO}-d_{6}\right) \delta 0.6-1.8$ $(\mathrm{m}, 20 \mathrm{H}), 2.8-3.2(\mathrm{~m}, 4 \mathrm{H}), 3.6-3.9(\mathrm{~m}, 3 \mathrm{H}), 6.7-$ $8.0(\mathrm{~m}, 14 \mathrm{H})$.

\subsection{Instrumentations}

${ }^{1} \mathrm{H}$ NMR spectroscopy was performed on a Bruker 200, 300, or $400 \mathrm{MHz}$ spectrometer. Elemental analyses were performed on an EA Heraeus Vario EL-3 analyzer. FTIR spectra were recorded using a Jasco-480 spectrometer. UV-vis analyses were performed on a Jasco V-570 UV-vis spectrophotometer. The number-average and weight-average molecular weight of the polymers was determined by a Waters GPC-480 system with a column of AM GPC Gel $(10 \mu \mathrm{m})$ from American Polymer Standard Company. Dimethylforamide (DMF) as eluent and polystyrene as standard were used in these experiments. TGA and DSC were performed on a TGA Perkin-Elmer TGA-7 and DSC Du Pont 2010 analyzer under a nitrogen atmosphere at a heating rate of $10^{\circ} \mathrm{C} \mathrm{min}^{-1}$. The thickness of the polymer films was measured using an Alpha step Dektak 3030 profilometer. Photoluminescence (PL) spectra of the polymers were recorded using a Hitachi-4500 spectrofluorometer. Electroluminescence was recorded by a Minolta CS-1000 instrument. The $I-V$ and $L-V$ characteristics of the devices were measured by integrating a Keithley 2400 source-meter as the voltage and current source and a Minolta CS1000 instrument as the Luminance detector. All the measurements and device fabrications were performed in air at room temperature under a dust-controlled environment.

\subsection{Device fabrication}

The PLED device structure was ITO/PEDOT:PSS(30nm)/PU(30nm)/MEH-PPV(50 nm)/ $\mathrm{Ca}(10 \mathrm{~nm}) / \operatorname{Ag}(100 \mathrm{~nm})$, which consisted of poly(ethylenedioxythiophene):poly(styrene sulfonic acid) (PEDOT:PSS) as the hole-injection layer 
(HIL), OPV-TDI, OPV-IPDI or OPV-H ${ }_{12} \mathrm{MDI}$ as the hole-transport layer (HTL), poly[2-methoxy5-(2'-ethyl-hexyloxy)-1,4-phenylene- $(E)$-vinylene] (MEH-PPV) as the emitting layer (EML), and finally $\mathrm{Ca} / \mathrm{Ag}$ as the cathode. The HOMO and LUMO of PEDOT:PSS is close to that of the ITO. Therefore, PEDOT:PSS was employed as HIL to increase hole-injection from the ITO anode to the EML in the latter study. Previous results revealed that the PEDOT:PSS layer has certain capability to resist the DMF etching and would not be significantly destroyed by the polar solvent in the following step of PU coating [15a]. On the other hand, low work function metal $(\mathrm{Ca})$ was chosen as electron injection layer (EIL) to facilitate electron injection from $\mathrm{Ag}$ cathode. In addition, a primitive device, without inserting any HIL and HTL, of ITO/MEH-PPV $(50 \mathrm{~nm}) / \mathrm{Ca}(10 \mathrm{~nm}) / \mathrm{Ag}(100$ $\mathrm{nm})$, as well as a standard device of ITO/PEDOT:PSS(30 nm)/MEH-PPV(50 nm)/Ca(10 nm)/ $\operatorname{Ag}(100 \mathrm{~nm})$ were fabricated as references. The ITO surface was cleaned by a sequence of actions, including sonication, rinsing in deionized water, Triton-100 water solution, deionized water, acetone and methanol. The hole-injection PEDOT:PSS layer was spin-coated on top of the ITO anode and dried on a hot plate at $130{ }^{\circ} \mathrm{C}$ for 30 min under vacuum. Each polymer solution for spin-coating, with the concentration of $5 \mathrm{mg} / \mathrm{mL}$ in DMF, was filtered through a membrane filter with the channel size of $0.45 \mu \mathrm{m}$. The PU solution was spin-coated onto the prepared PEDOT:PSS/ITO anode and dried under reduced pressure for $30 \mathrm{~min}$ at $120^{\circ} \mathrm{C}$. The deposition rates for $\mathrm{Ca}$ and $\mathrm{Ag}$ cathodes were set at $1 \AA / \mathrm{s}$ and $4 \AA / \mathrm{s}$, giving an active area of $0.1256 \mathrm{~cm}^{2}$. The thickness for each layers were measured by an Alpha step instrument.

\subsection{Fabrication of flexible PLED devices}

The flexible PET/ITO plates used in the experiments have an electrical sheet resistance of $300 \Omega$ / $\square$, being cut into $2.5 \mathrm{~cm} \times 2.5 \mathrm{~cm}$ format. The flexible ITO plates were first fixed onto a piece of glass plate by using two-sided Scotch tape before spincoating, and then a layer of PEDOT:PSS was coated at the spin-rate of $5000 \mathrm{rpm}$. The plates were then baked at $120^{\circ} \mathrm{C}$ under vacuum for $30 \mathrm{~min}$ and cooled. A layer of PU ( $5 \mathrm{mg} / \mathrm{ml}$ in dried DMF) was then coated on top at $4000 \mathrm{rpm}$. The plates were then baked again at $120^{\circ} \mathrm{C}$ under vacuum for $30 \mathrm{~min}$. A layer of yellow-light-emitting PPV was then coated $(5 \mathrm{mg} / \mathrm{ml}$ in dried toluene $)$ at $4000 \mathrm{rpm}$ and also baked at $120^{\circ} \mathrm{C}$ under vacuum for $30 \mathrm{~min}$. The $\mathrm{Ca}$ cathode was deposited under vacuum, at a rate of $1 \AA / \mathrm{s}$, till $10 \mathrm{~nm}$ thickness, followed by $\mathrm{Ag}$, at a rate of $4 \AA / \mathrm{s}$, up to the $100 \mathrm{~nm}$ thickness. The device performances were measured under ambient conditions.

\section{Results and discussion}

\subsection{Monomer synthesis}

The preparation route of OPV monomer is illustrated in Scheme $1[13,15]$. OPV was prepared in three steps from para-xylene. Radical bromination of para-xylene led to $\alpha, \alpha^{\prime}$-dibromo-para-xylene [17] in $51 \%$ yield. Treatment of $\alpha, \alpha^{\prime}$-dibromo-paraxylene with triethylphosphite afforded bis(diethylphosphonate) $1(66 \%)$ [18] that was further condensed with 2-hydroxybenzaldehyde under the Wadsworth-Emmons-Wittig conditions to give the target OPV monomer (74\%) [19]. Noteworthy to mention that only $(E)$-isomer would be obtained under the Wadsworth-Emmons-Wittig condensation conditions. Reaction under $\mathrm{N}_{2}$ atmosphere in the last step was crucial because brownish contaminants that were difficult to remove would be generated without an inert atmosphere protection.

\subsection{Polymer characterization}

The polar polyurethanes were prepared from condensation polymerization of the OPV monomer with commercially available diisocyanates such as TDI, IPDI or $\mathrm{H}_{12} \mathrm{MDI}$ in dried DMF to give polymers OPV-TDI, OPV-IPDI or OPV-H ${ }_{12} \mathrm{MDI}$, respectively (Scheme 2). As shown in Fig. 1, upon reaction, the IR-absorptions of the $-\mathrm{NCO}$ group and the $\mathrm{ArOH}$ groups disappeared at $2260 \mathrm{~cm}^{-1}$ and $3500 \mathrm{~cm}^{-1}$, respectively. Instead an absorption of the $-\mathrm{NH}$ group appeared at $3330 \mathrm{~cm}^{-1}$. These results implied that the urethane linkages were formed completely. The molecular weight of the resultant polymers and their thermal behavior, including $T_{\mathrm{g}}$ and $T_{\mathrm{d}}$, were summarized in Table 1 . The molecular weight of the polymers was determined by gel-permeation chromatography (GPC) analysis against polystyrene standard in DMF. The energy level of the highest occupied molecular orbital (HOMO) was obtained by photoelectron spectrometric measurements [20] (Riken Keiki AC2 ) in which the HOMO energy level of the polymeric 


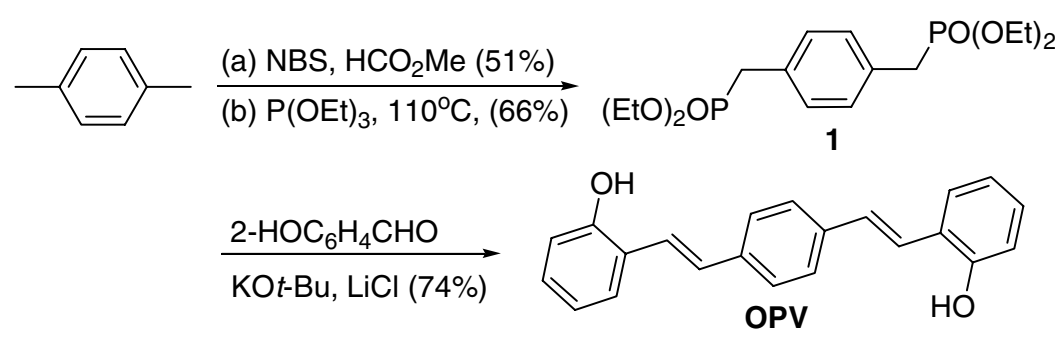

Scheme 1. Synthesis of the OPV monomer.

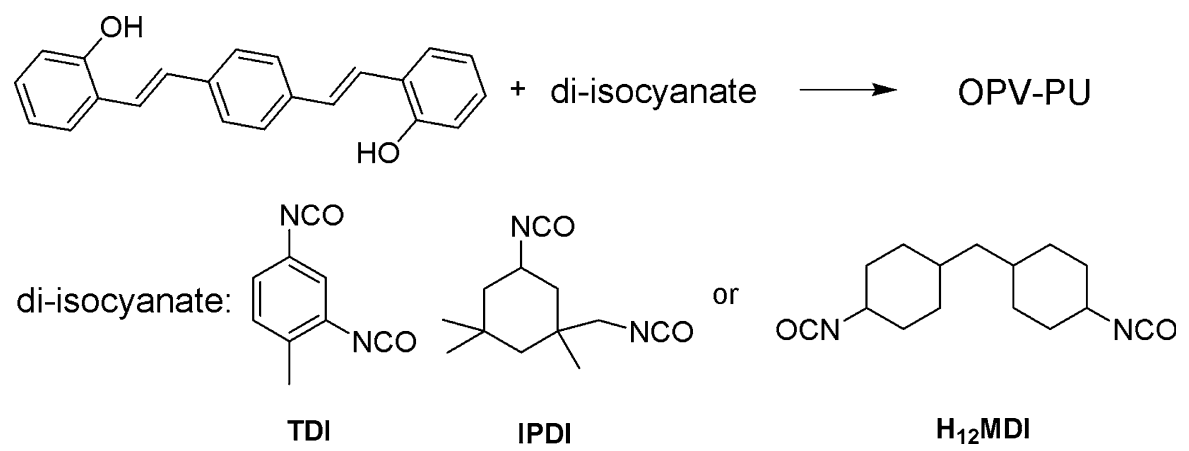

Scheme 2. Condensation polymerization of the OPV monomer with diisocyanates.

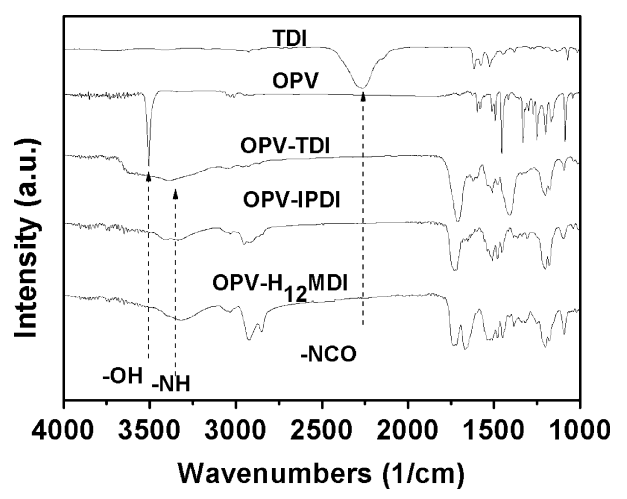

Fig. 1. Infrared (IR) spectra of TDI, OPV-TDI, OPV-IPDI and OPV-H ${ }_{12} \mathrm{MDI}$. films was directly measured. The characterization and optical properties of the studied polymers in diluted solutions and in solid films were also listed in Table 1.

\subsection{Optical properties}

Fig. 2 exhibits UV-vis absorption and PL spectra of the three PU polymer films. Compared with OPV-IPDI and OPV- $\mathrm{H}_{12} \mathrm{MDI}$, both absorption and PL spectra of OPV-TDI were red-shifted The half-width of PL emission band of the OPV-TDI was the largest among the PUs we studied. These phenomena may arise from the phenyl and OPV/

Table 1

Characterization and optical properties of PUs

\begin{tabular}{lcllllll}
\hline & $M_{\mathrm{w}}\left(\times 10^{-3}\right)$ & $\mathrm{DP}^{\mathrm{a}}$ & $T_{\mathrm{g}}\left({ }^{\circ} \mathrm{C}\right)$ & $T_{\mathrm{d}}\left({ }^{\circ} \mathrm{C}\right)$ & $\mathrm{HOMO}^{\mathrm{d}} / \mathrm{LUMO}^{\mathrm{e}}(\mathrm{eV})$ & $\mathrm{UV}(\mathrm{nm})^{\mathrm{b}} \max$ & $\mathrm{UV}^{(\mathrm{nm})}{ }^{\mathrm{c}} \mathrm{max} / \mathrm{edge}$ \\
\hline OPV-TDI & 9.4 & 2.12 & 105 & 300 & $-5.71 /-3.00$ & 388 & $399 / 458$ \\
OPV-IPDI & 9.7 & 2.57 & 84 & 276 & $-5.62 /-2.67$ & 372 & $378 / 421$ \\
OPV-H $_{12}$ MDI & 10.3 & 2.39 & 78 & 261 & $-5.61 /-2.75$ & 372 & $376 / 434$ \\
\hline
\end{tabular}

${ }^{a}$ From GPC.

b Solution.

c Film.

${ }^{\mathrm{d}}$ From AC-2 measurement.

e Based on the optical band gap of film. 


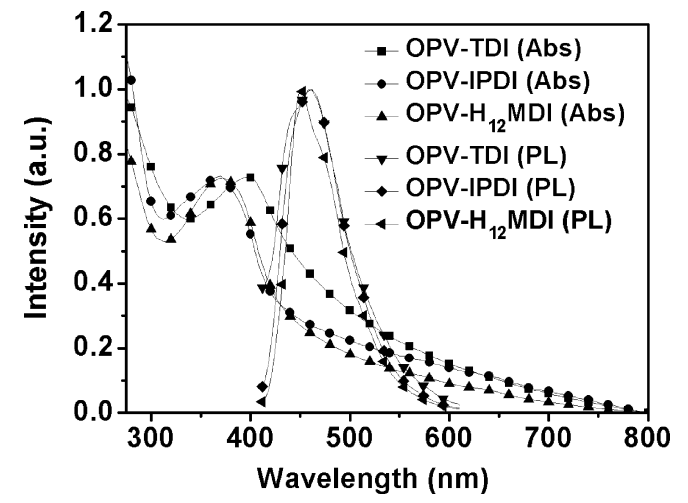

Fig. 2. UV-vis absorption and PL spectra of OPV-TDI, OPVIPDI and OPV-H ${ }_{12}$ MDI polymer films.

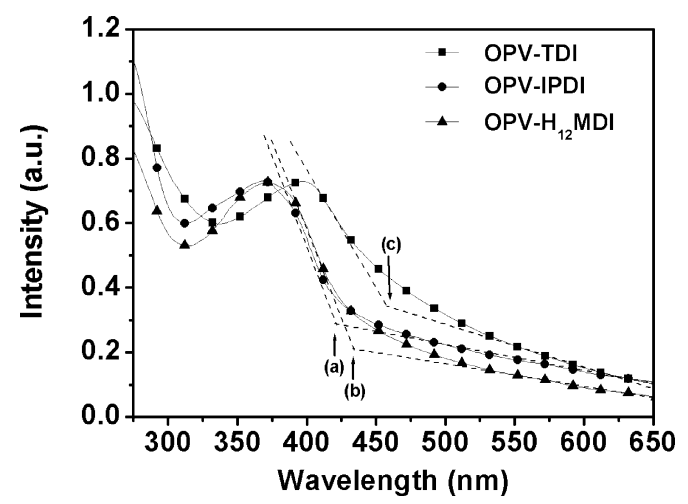

Fig. 3. UV-vis absorption spectra of OPV-TDI, OPV-IPDI and OPV- $\mathrm{H}_{12} \mathrm{MDI}$ in solid-state films: (a) UV onset for OPV-IPDI: (b) UV onset for OPV-H $\mathrm{H}_{12} \mathrm{MDI}$ : (c) UV onset for OPV-TDI.

TDI $\pi-\pi$ interactions. The optical band gaps of the polymers were estimated as $2.71,2.95$ and $2.86 \mathrm{eV}$, respectively, from the onset of the UV-vis absorption band, shown in Fig. 3, at $458 \mathrm{~nm}$ for OPV-TDI, $421 \mathrm{~nm}$ for OPV-IPDI and $434 \mathrm{~nm}$ for OPV-H ${ }_{12}$ MDI. The lowest unoccupied molecular orbital (LUMO) energy levels were then calculated on the basis of their HOMO energy levels and the values of optical band gap of the polymers [21].

\subsection{Thermal properties}

The thermal behaviors of the polymers have been studied by differential scan calorimetry (DSC) (Fig. 4) and thermogravimetric analysis (TGA) (Fig. 5). OPV-H $\mathrm{H}_{12} \mathrm{MDI}$ exhibited a relatively low glass transition temperature $\left(T_{\mathrm{g}}\right)$ of $78{ }^{\circ} \mathrm{C}$ in comparison to OPV-TDI that showed a higher $T_{\mathrm{g}}$ of $105^{\circ} \mathrm{C}$. It is reasonable because benzene ring usu-

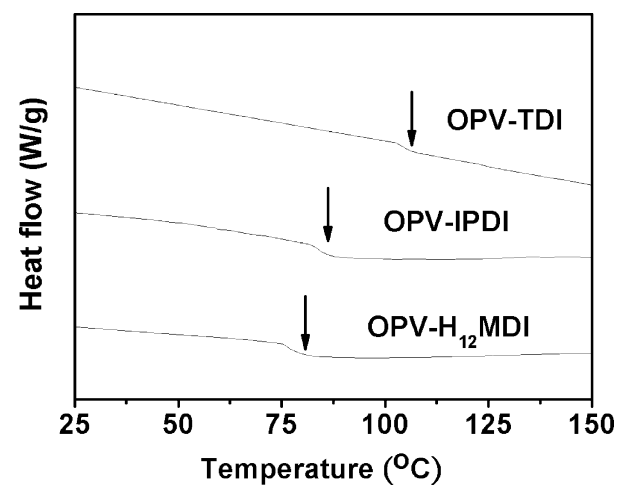

Fig. 4. Differential scan calorimetry curves of OPV-TDI, OPVIPDI and OPV- $\mathrm{H}_{12} \mathrm{MDI}$.

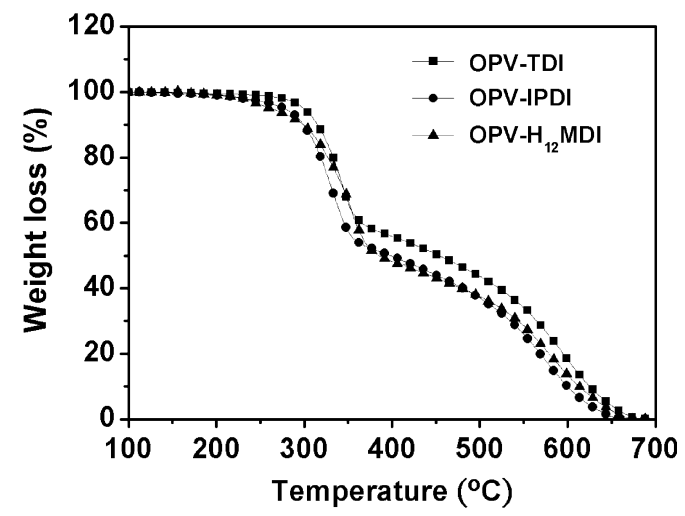

Fig. 5. Thermogravimetric analysis of OPV-TDI, OPV-IPDI and OPV-H ${ }_{12} \mathrm{MDI}$.

ally has higher rigidity than the cyclohexyl group. The lower $T_{\mathrm{g}}$ of $\mathrm{OPV}-\mathrm{H}_{12} \mathrm{MDI}$ was attributed to the relatively flexible segmental mobility of the dual cyclohexyl units per repeating unit. OPV-IPDI also showed relatively high flexibility than OPV-TDI. The $T_{\mathrm{g}}$ of $84{ }^{\circ} \mathrm{C}$ was recorded that was close to that of OPV-H $\mathrm{H}_{12} \mathrm{MDI}$. As for the $T_{\mathrm{d}}$, there was a similar trend as $T_{\mathrm{g}}$ did.

\subsection{Electroluminescence properties}

PLED devices on ITO glass or on PET/ITO substrates have been studied. OPV-TDI, OPV-IPDI, and OPV- $\mathrm{H}_{12} \mathrm{MDI}$ were first applied as the HTL materials on ITO glass substrates for PLED fabrication. Totally five devices, denoted as devices 1-5, were examined and their device structures are listed in Table 2. The luminance-voltage and the current efficiency-voltage plots of devices $1-5$ are shown in Figs. 6 and 7, respectively and their performance 
Table 2

PLED structure of devices $1-5$ on ITO glass

\begin{tabular}{|c|c|c|c|c|c|c|}
\hline & HIL (nm) & HTL (nm) & & \multirow{2}{*}{$\begin{array}{l}\text { EML (nm) } \\
\text { MEH-PPV }\end{array}$} & \multicolumn{2}{|c|}{ Cathode (nm) } \\
\hline & PEDOT:PSS & & & & $\mathrm{Ca}$ & $\mathrm{Ag}$ \\
\hline Device 1 & N/A & N/A & - & 50 & 10 & 100 \\
\hline Device 2 & 30 & N/A & - & 50 & 10 & 100 \\
\hline Device 3 & 30 & OPV-TDI & 30 & 50 & 10 & 100 \\
\hline Device 4 & 30 & OPV-IPDI & 30 & 50 & 10 & 100 \\
\hline Device 5 & 30 & $\mathrm{OPV}-\mathrm{H}_{12} \mathrm{MDI}$ & 30 & 50 & 10 & 100 \\
\hline
\end{tabular}

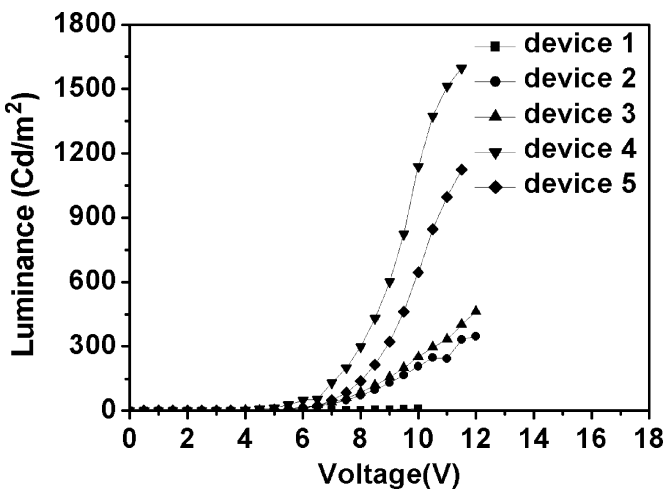

Fig. 6. Characteristic brightness-voltage curves of devices 1-5.

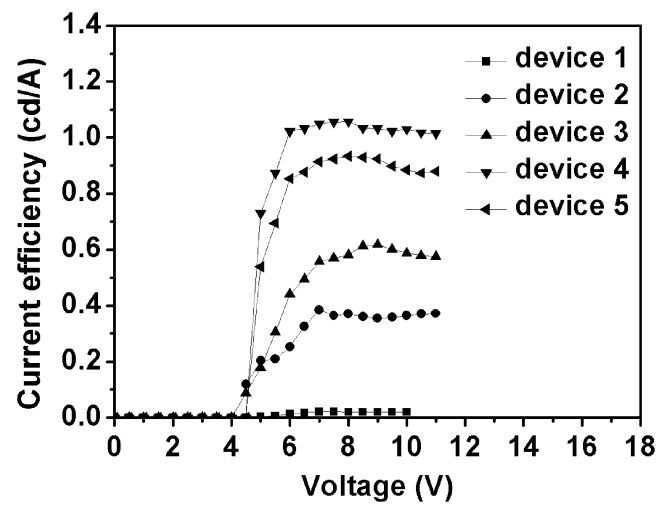

Fig. 7. Current efficiency-voltage characteristic of devices 1-5.

Table 3

Electroluminescence performance of devices 1-5 on ITO glass

\begin{tabular}{llcl}
\hline & $\begin{array}{l}\text { Turn-on } \\
\text { voltage }(\mathrm{V})\end{array}$ & $\begin{array}{l}\text { Maximum } \\
\text { brightness }\left(\mathrm{cd} / \mathrm{m}^{2}\right)\end{array}$ & $\begin{array}{l}\text { Efficiency } \\
(\mathrm{cd} / \mathrm{A})\end{array}$ \\
\hline Device 1 & 5.0 & 10 & 0.02 \\
Device 2 & 4.5 & 348 & 0.39 \\
Device 3 & 4.5 & 463 & 0.62 \\
Device 4 & 3.5 & 1598 & 1.06 \\
Device 5 & 4.0 & 1125 & 0.93 \\
\hline
\end{tabular}

are summarized in Table 3. Compared with the single-layer reference device 1, the PLED with either a layer of PEDOT:PSS only (device 2) or having an extra OPV-TDI, OPV-IPDI or OPV-H ${ }_{12}$ MDI layer on top (devices 3-5) could dramatically enhance the maximum brightness and current efficiency. Such enhancements may due to more balanced hole-electron transportation to the EML of the device. Under these conditions, the current efficiency was significantly improved. To act as a high-performance HTL layer, the material should be a good hole-transport layer with electron-block properties. In addition, the contact between the layers must be good so that the interfacial resistance could be minimized. The OPV fragments might play an important role for hole-transport process in the PU matrix. Related prior work using poly(para-phenylene-vinylene) as hole-transport layers have been reported for multi-layer PLED applications [15]. On the other hand, the PU layer may also act as an electron-blocking layer, helping to confine the excitons in the emitting layer and improving recombination in MEH-PPV. This point of view may be valid due to the higher lying LUMO of the PUs. It has been reported that the energy level of the LUMO of MEH-PPV is $-2.9 \mathrm{eV}$ [15d], which is lower than that of OPV-IPDI $(-2.67 \mathrm{eV})$ and of OPV- $\mathrm{H}_{12} \mathrm{MDI}(-2.75 \mathrm{eV})$. In addition, the dipolar urethane may have a good contact with the ionic PEDOT:PSS layer through dipole-moment interactions. Interfacial contact between layers is important for the charge transport process in the multilayer devices. Poor contact between layers would lead to high electrical resistance. In consideration the ionic PEDOT:PSS as a polar polymeric layer, the polymers containing polar urethane groups should have good adhesion to the PEDOT:PSS surface. Furthermore, the presence of the polar groups at the interface may also help to reduce the hole-injection energy barrier. It has been reported that grafting of dipolar molecules on the ITO surface would enhance the PLED performance [16d]. Other theory also suggested that alignment of 
Table 4

PLED structure of the flexible PLED devices 6 and 7

\begin{tabular}{|c|c|c|c|c|c|c|}
\hline & HIL (nm) & HTL (nm) & & \multirow{2}{*}{$\begin{array}{l}\text { EML (nm) } \\
\text { Yellow PPV }\end{array}$} & \multicolumn{2}{|c|}{ Cathode (nm) } \\
\hline & PEDOT:PSS & & & & $\mathrm{Ca}$ & $\mathrm{Ag}$ \\
\hline Device 6 & 30 & N/A & - & 50 & 10 & 100 \\
\hline Device 7 & 30 & OPV-IPDI & 30 & 50 & 10 & 100 \\
\hline
\end{tabular}

dipolar molecules along the interface would significantly alter the work function of the surface [22]. Additionally, it has long been known that introduction of ionic species into organic solvents would lead to solvent-dipole reorganization. Through the solvent reorganization, the ionic species could be stabilized [23]. Therefore, when a hole was injected from the PEDOT:PSS surface into the OPV segment, the reorientation of the adjacent urethane groups was expected to induce a stabilization effect on the process, helping the hole-injection into the PU layers. Such mechanism may be the key factor for reducing driving voltage and improving current efficiency.

The device performance of the PLED devices are summarized in Table 3. One can see that devices 3-5 had lower turn-on voltage and much higher current efficiency than the reference devices 1 and 2 . The effects of the PU layer on the turn-on voltage were definitely essential. The turn-on voltage, defined as the operating voltage at $1 \mathrm{~cd} / \mathrm{m}^{2}$, significantly dropped from $5 \mathrm{~V}$ of the reference device 1 to $4.5 \mathrm{~V}$ for reference device $2,4.5 \mathrm{~V}$ for device 3 , $3.5 \mathrm{~V}$ for device 4 , and $4 \mathrm{~V}$ for device 5 , respectively. Device 4 showed superior hole-transport capability with the OPV-IPDI as a hole-transport layer and had the maximum current efficiency of $1.06 \mathrm{~cd} / \mathrm{A}$. Therefore, OPV-IPDI is the most suitable HTL causing the balanced hole and electron injection in the emitting layer. Under the best conditions, the OPV-IPDI achieved 53 times and 2.72 times of current efficiency enhancement and $1.5 \mathrm{~V}$ and $1 \mathrm{~V}$ voltage reduction of the turn-on voltage, respectively, when compared against the bare ITO (reference device 1) and ITO/PEDOT (reference device 2) as anode, This approach could be applied for flexible PLED fabrication (Table 4). The flexible PLED device performances are summarized in Table 5. In these flexible devices, a phenyl-substituted poly (para-phenylenevinylene) copolymer ("super-yellow") has been used as the emitting layer [12d]. Device 7 showed superior hole-transport capability with the OPV-IPDI as a hole-transport layer and had the maximum brightness of $2800 \mathrm{~cd} / \mathrm{m}^{2}$ and
Table 5

Electroluminescence performance of the flexible PLED devices 6 and 7

\begin{tabular}{llcl}
\hline & $\begin{array}{l}\text { Turn-on } \\
\text { voltage }(\mathrm{V})\end{array}$ & $\begin{array}{l}\text { Maximum } \\
\text { brightness }\left(\mathrm{cd} / \mathrm{m}^{2}\right)\end{array}$ & $\begin{array}{l}\text { Efficiency } \\
(\mathrm{cd} / \mathrm{A})\end{array}$ \\
\hline Device 6 & 4.0 & 703 & 0.7 \\
Device 7 & 3.0 & 2800 & 2.1 \\
\hline
\end{tabular}

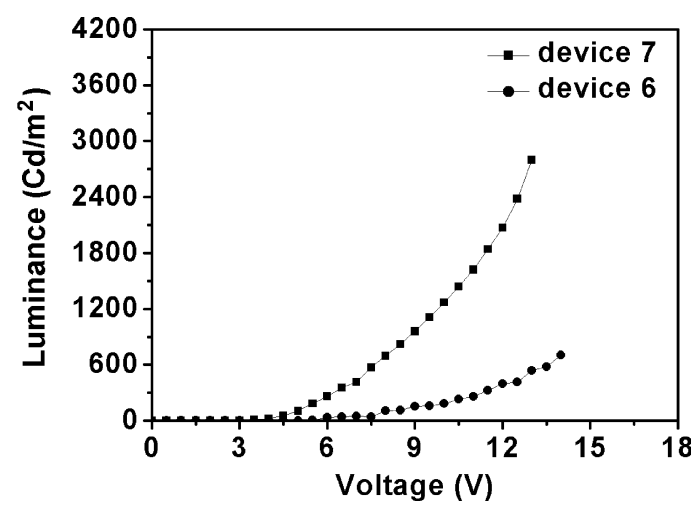

Fig. 8. Characteristic brightness-voltage curves of the flexible devices 6 and 7 .

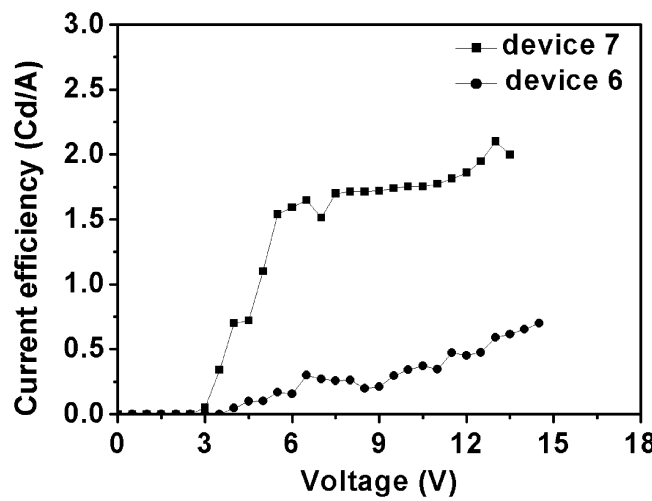

Fig. 9. Current efficiency-voltage characteristic of the flexible devices 6 and 7 .

maximum current efficiency of $2.1 \mathrm{~cd} / \mathrm{A}$ in comparison to the device 6 which had the maximum brightness of only $703 \mathrm{~cd} / \mathrm{m}^{2}$ and maximum current efficiency of $0.7 \mathrm{~cd} / \mathrm{A}$ (Figs. 8 and 9). 
The electroluminescence spectra of MEH-PPV devices are shown in Fig. 10. The EL spectra illustrated that the maximum emission peaked at $585 \mathrm{~nm}$ with the luminescence features almost identical with the literature data $[15 \mathrm{~d}]$. The emission did not shift even when the driving voltage increased from $6 \mathrm{~V}$ to $9 \mathrm{~V}$, indicating that the exciton recombination was still confined within the MEH-PPV layer. Meanwhile, the spectral bleaching phenomena had not been observed when the applied voltage was increased. As we mentioned before, due to the higher lying LUMO and the lower lying HOMO of the PU layer, the excitons confinement in the MEH-PPV layer was reasonable. Therefore, the recombination zone would not cross-over to the PU layer. It could explain why the spectral properties of the MEH-PPV device could be maintained when the applied voltage was increased. Fig. 11 illustrates the EL spectra of the flexible devices.

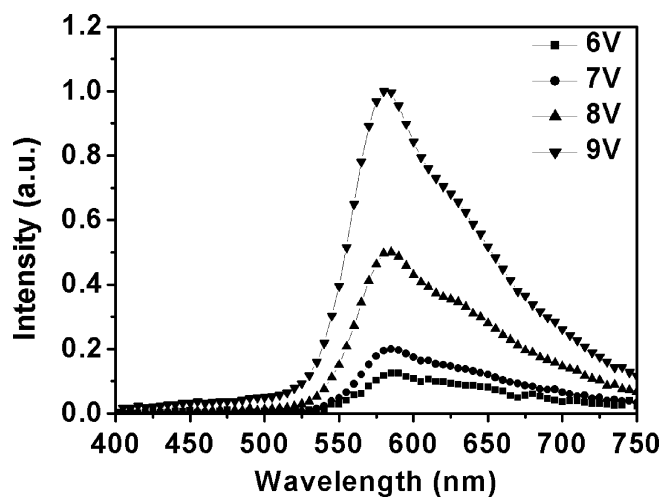

Fig. 10. The electroluminescence spectra of device 4 at various driving voltage.

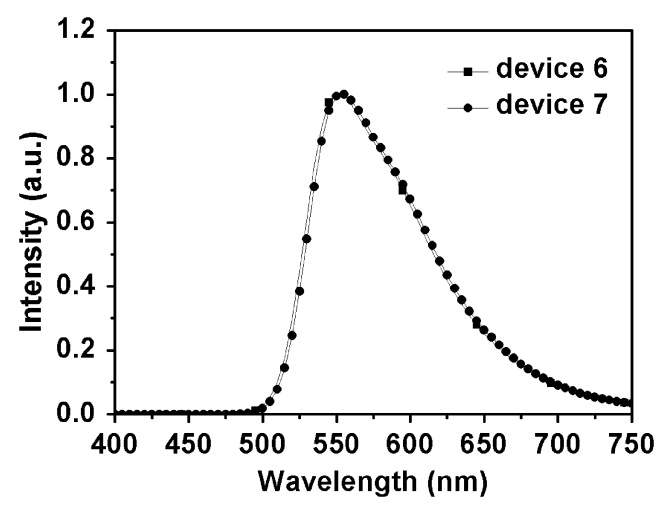

Fig. 11. The electroluminescence spectra of the flexible devices 6 and 7 at $9 \mathrm{~V}$.

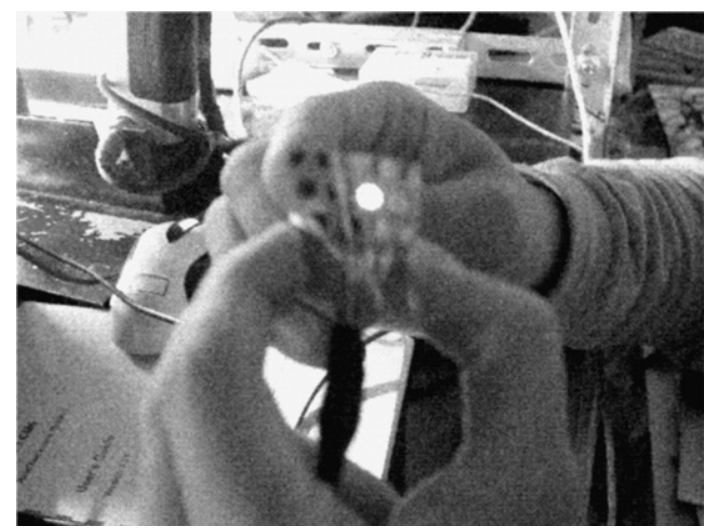

Fig. 12. The flexible PLED with PU hole-transport modification layer at $9 \mathrm{~V}$.

The maximum emission peaked at $555 \mathrm{~nm}$ was observed. These results also indicated the PU layer would not affect the emitting layer properties. The picture of the flexible device operating at $9 \mathrm{~V}$ was shown in Fig. 12. Bright EL was clearly observed.

\section{Conclusion}

In short, the high-performance hole-transport polyurethanes (PUs) have been demonstrated as they can greatly achieve charge-balanced condition to reduce the driving voltage and to improve the current efficiency both on the glass and flexible PET substrates. Previous research results revealed that the OPV-PU has a good hole-transport property in the hole-only device study [15a]. We believed that the excellent hole-transport capability together with PUs' good solubility in polar solvents made the OPV-IPDI a most potential candidate for use in the multi-layer PLED devices by solution processing techniques. All this suggested that IPDI is a suitable diisocyanate candidate for further PU derived lightemitting-diode investigations.

\section{Acknowledgements}

This work was supported by Ministry of Economic Affairs (93-EC-17-A-08-S1-0015), National Science Council of Taiwan (NSC 95-2113-M-002020) and Advanced Polymer Nano Technology Research Center.

\section{References}

[1] Burroughes JH, Bradley DDC, Brown AR, Marks RN, Mackay K, Friend RH, et al. Nature 1990;347:539. 
[2] Ohmori Y, Uchida M, Muro K, Yoshino K. Jpn J Appl Phys 1991;30:L1938.

[3] Braun D, Heeger A. J Appl Phys Lett 1991;58:1982.

[4] (a) Gu G, Shen Z, Burrows PE, Forrest SR. Adv Mater 1997;9:725-8;

(b) Tsutsui T, Fujita K. Adv Mater 2002;14:949-52;

(c) Yang Y, Huang Q, Metz AW, Ni J, Jin S, Marks TJ, et al. Adv Mater 2004;16:321-4;

(d) Lee KJ, Motala MJ, Meitl MA, Childs WR, Menard E, Shim AK, et al. Adv Mater 2005;17:2332-6;

(e) Hide F, Díaz-García MA, Schwartz BJ, Heeger A. J Acc Chem Res 1997;30:430;

(f) Greenham NC, Friend RH. In: Enhrenreich H, Spaepen F, editors. Solid state physics, vol. 49. San Diego: Academic; 1995. p. 1-149;

(g) Gustafsson G, Cao Y, Treacy GM, Klavetter F, Colaneri N, Heeger AJ. Nature 1992;357:477.

[5] Qiu Y, Gao Y, Wei P, Wang L. Appl Phys Lett 2002;80:2628.

[6] Baldo MA, Lamansky S, Burrows PE, Thompson ME, Forrest SR. Appl Phys Lett 1999;75:4.

[7] Xie ZY, Hung LS, Lee ST. Appl Phys Lett 2001;79:1048.

[8] Sprengard R, Bonrad K, Däubler TK, Frank T, Hagemann V, Köhler I, et al. Proc SPIE 2004;5519:173-83.

[9] Ho G-K, Meng H-F, Lin S-C, Horng S-F, Hsu C-S, Chen L-C, et al. Appl Phys Lett 2004;85:4576-8.

[10] Nuyken O, Bacher E, Braig T, Fáber R, Mielke F, Rojahn M, et al. Design Monom Polym 2002;5:195-210.

[11] (a) Ma W, Iyer PK, Gong X, Liu B, Moses D, Bazan GC, et al. Adv Mater 2005;17:274-7;

(b) Gong X, Wang S, Moses D, Bazan GC, Heeger A. J Adv Mater 2005;17:2053-8;

(c) Tonzola CJ, Alam MM, Jenekhe SA. Adv Mater 2002;14:1086;

(d) Cui Y, Zhang X, Jenekhe SA. Macromolecules 1999;32:3824.

[12] (a) Burn PL, Grice AW, Tajbakhsh A, Bradley DDC, Thomas AC. Adv Mater 1997;9:1171-4;

(b) Kraft A, Grimsdale AC, Holmes AB. Angew Chem Int Ed 1998;37:402-28;

(c) Becker H, Spreitzer H, Kreuder W, Kluge E, Schenk H, Parker I, et al. Adv Mater 2000;12:130-3; (d) Edman L, Pauchard M, Moses D, Heeger AJ. J Appl Phys 2004;95(8):4357;

(e) Ouyang J, Guo TF, Yang Y, Higuchi H, Yoshiko M, Nagatsuka T. Adv Mater 2002;14:915.

[13] Bernius MT, Inbasekaran M, O'Brien J, Wu W. Adv Mater 2000;12:1737-50.

[14] Randall D, Lee S, editors. The polyurethanes book. New York: Wiley; 2002.

[15] (a) Kuo C-H, Lee J-H, Leung M-k, Hsieh K-H. Chem Mater 2006;18:4121-9;

(b) Jenekhe SA, Zhang X, Chen L. Chem Mater 1997;9:409;

(c) Zhang X, Jenekhe SA. Macromolecules 2000;33:2069;

(d) Maksudul M, Jenekhe SA. Chem Mater 2002;14:4775.

[16] (a) Park JH, Park OO, Yu JW, Kim JK, Kim YC. Appl Phys Lett 2004;84:1783;

(b) Wang H-L, Wen T-C. Mater Chem Phys 2003;82:341-6;

(c) Ishchenko A. Polym Adv Technol 2002;13:744-52;

(d) Lim H, Noh JY, Lee GH, Lee SE, Jeong H, Lee K, et al. Thin Solid Films 2000;363:152-5;

(e) Jeong H, Zou D, Tsutsui T, Ha C-S. Thin Solid Films 2000;363:279-81;

(f) Lee TW, Park OO. Appl Phys Lett 2000;76:3161-3;

(g) Jeong H, Ha C-S. Mol Cryst Liquid Cryst Sci Technol, Sect A 1999;337:349-52.

[17] Sket B, Zupan MJ. Org Chem 1986;51:929-31.

[18] Kauffman JM, Moyna G. J Org Chem 2003;68:839-53.

[19] Tewari RS, Kumari N, Kendurkar PS. Indian J Chem (B) 1977;15:753-5.

[20] (a) Trigwell S, Grable N, Yurteri CU, Mazumder MK, Seo S. Surf Interf Anal 1998;26:483-9;

(b) Nakajima Y, Yamashita D. Jpn Patent JP2005257538, CAN 143:338608, AN 2005:1023803;

(c) Yoshino K, Onoda M, Manda Y, Yokoyama M. Jpn J Appl Phys 1988;27:L1606-8.

[21] Ishii H, Sugiyama K, Ito E, Seki K. Adv Mater 1999;11: 605.

[22] Ishii H, Seki K. Conjugated polymer and molecular interfaces. In: Salaneck WR, Seki K, Kahn A, Pireaux JJ, editors. New York: Marcel Dekker; 2002. p. 293-350 [chapter 10].

[23] Reichardt C. Solvents and solvent effects in organic chemistry. Weinheim: Wiley-WCH; 2003. 